\title{
Insight into the Role of Facultative Bacteria Stimulated by Microaeration in Continuous Bioreactors Converting LCFA to Methane
}

\author{
M. Salomé Duarte, ${ }^{\dagger}$ Sérgio A. Silva, ${ }^{\dagger}$ Andreia F. Salvador, ${ }^{\dagger}$ Ana J. Cavaleiro, ${ }^{\dagger}$ Alfons J. M. Stams, ${ }^{\dagger, \dagger}$ \\ M. Madalena Alves, ${ }^{\dagger}$ and M. Alcina Pereira* ${ }^{\dagger}{ }^{\dagger}$ \\ ${ }^{\dagger}$ Centre of Biological Engineering, University of Minho, Campus de Gualtar, 4710-057 Braga, Portugal \\ ${ }^{\ddagger}$ Laboratory of Microbiology, Wageningen University, Stippeneng 4, 6708 WE Wageningen, The Netherlands
}

Supporting Information

ABSTRACT: Conversion of unsaturated long chain fatty acids (LCFA) to methane in continuous bioreactors is not fully understood. Palmitate (C16:0) often accumulates during oleate (C18:1) biodegradation in methanogenic bioreactors, and the reason why this happens and which microorganisms catalyze this reaction remains unknown. Facultative anaerobic bacteria are frequently found in continuous reactors operated at high LCFA loads, but their function is unclear. To get more insight on the role of these bacteria, LCFA conversion was studied under microaerophilic conditions. For that, we compared bioreactors treating oleate-based wastewater (organic loading

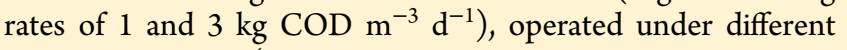
redox conditions (strictly anaerobic-AnR, $-350 \mathrm{mV}$; micro-

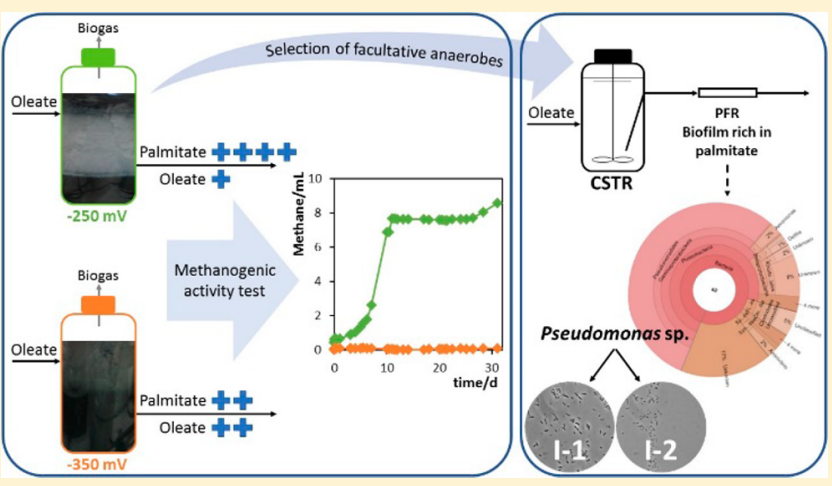
aerophilic-MaR, $-250 \mathrm{mV}$ ). At the higher load, palmitate accumulated 7 times more in the MaR, where facultative anaerobes were more abundant, and only the biomass from this reactor could recover the methanogenic activity after a transient inhibition. In a second experiment, the abundance of facultative anaerobic bacteria, particularly Pseudomonas spp. (from which two strains were isolated), was strongly correlated $(p<0.05)$ with palmitate-to-total LCFA percentage in the biofilm formed in a continuous plug flow reactor fed with very high loads of oleate. This work strongly suggests that microaeration stimulates the development of facultative bacteria that are critical for achieving LCFA conversion to methane in continuous bioreactors. Microbial networks and interactions of facultative and strict anaerobes in microbial communities should be considered in future studies.

\section{INTRODUCTION}

Under methanogenic conditions, long chain fatty acids (LCFA) can be biodegraded syntrophically by communities of acetogenic bacteria that perform $\beta$-oxidation and hydrogenotrophic methanogens that guarantee hydrogen concentrations at very low levels. ${ }^{1}$ For unsaturated LCFA, although the possibility of direct $\beta$-oxidation is not excluded, ${ }^{2,3}$ a mechanism starting with chain saturation followed by $\beta$-oxidation has been suggested by Weng and Jeris (1976). ${ }^{4}$ Nonetheless, stearate (C18:0) formation from oleate (C18:1) degradation was only occasionally observed and at low concentrations. 5 The accumulation of stearate and palmitate (50:50\% total LCFA) was reported by Broughton et al. $(1998)^{7}$ during the anaerobic digestion of sheep tallow and by Cavaleiro et al. (2009) $)^{8}$ during a stepwise feeding start-up of a reactor treating an oleate-based wastewater. More frequently, significant accumulation of palmitate (C16:0) occurs, associated to the sludge, when continuous anaerobic bioreactors are fed with oleate. ${ }^{5,9,10}$ The main mechanisms of palmitate accumulation are well described and include adsorption, entrapment in the filamentous structure of the sludge or precipitation. ${ }^{11}$ Under those conditions, oleate consumption is usually a fast process, palmitate accumulates and its further degradation proceeds slowly, raising the hypothesis that two different metabolic routes may be involved in the complete oleate degradation to methane. ${ }^{12}$ Accumulation of $\mathrm{C}_{n-2}$ saturated LCFA from $\mathrm{C}_{n}$ unsaturated LCFA suggests that $\beta$-oxidation is interrupted after just one cycle but the reason why this happens is not yet understood. Regarding this phenomenon, two major findings have been reported recently: (1) the conversion of oleate to palmitate in anaerobic bioreactors can be independent of the activity of methanogens, since palmitate still accumulates in reactors in which methanogenesis was inhibited; ${ }^{12}$ (2) the relative abundance of several groups of facultative anaerobic bacteria increased in non-methanogenic bioreactors where accumulation of palmitate from oleate took place. ${ }^{12}$ Facultative anaerobic bacteria are also frequently found in methanogenic

Received: February 15, 2018

Revised: April 23, 2018

Accepted: May 15, 2018

Published: May 15, 2018 


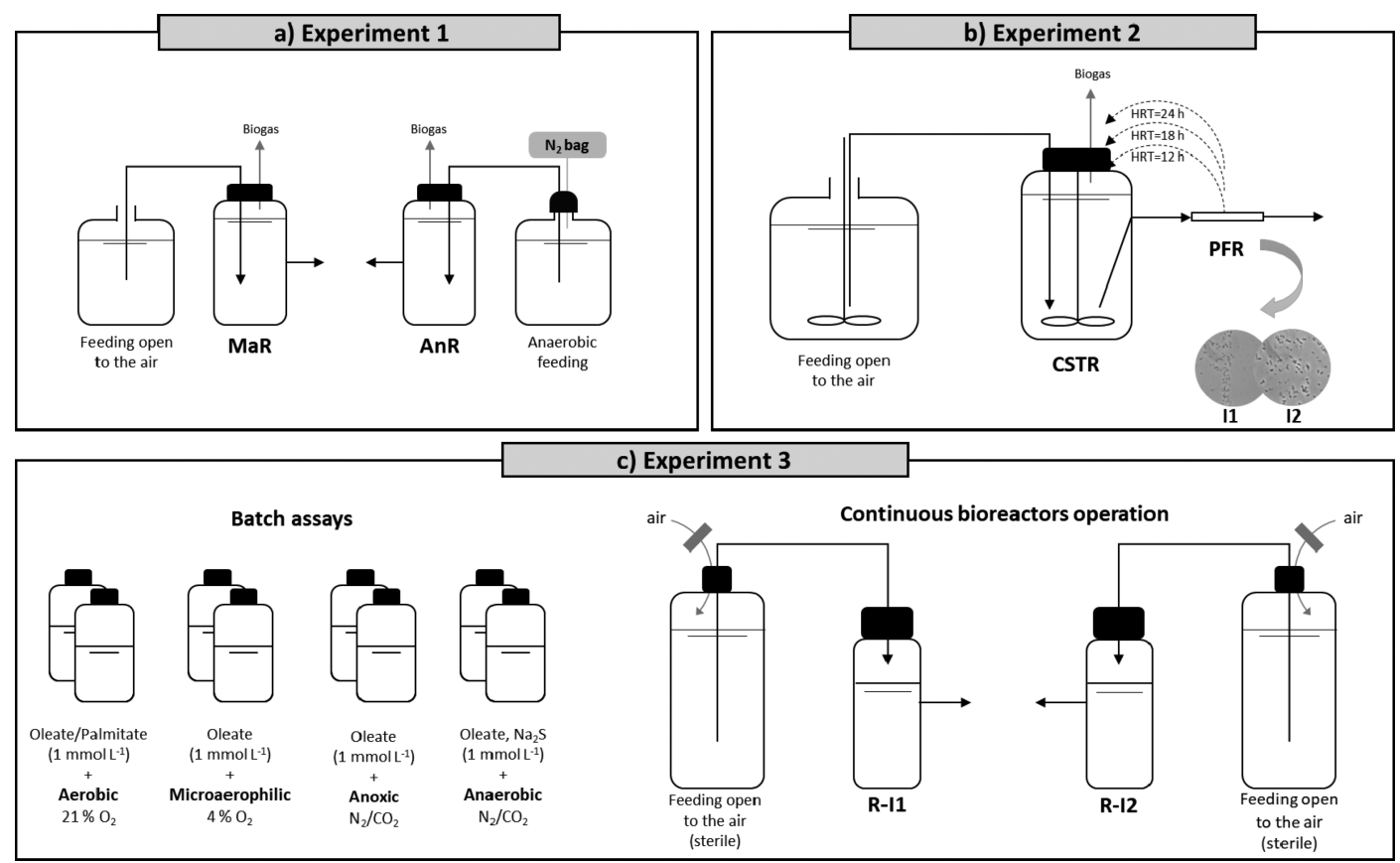

Figure 1. Schematic diagram of the experimental setup of experiment 1 (a), experiment 2 (b) and experiment 3 (c).

bioreactors treating oleate-based wastewater. ${ }^{13,14}$ This strongly suggests that facultative anaerobic bacteria may play a major role in LCFA degradation in anaerobic reactors.

The involvement of facultative anaerobes in hydrolysis and acidogenesis steps of anaerobic digestion $(\mathrm{AD})$, that culminate in the production of substrates for the methanogens, is long recognized. ${ }^{15,16}$ Facultative bacteria also protect strict anaerobes like methanogens by rapidly consuming traces of oxygen entering the system. ${ }^{17,18}$ The benefit of microaeration to accelerate and extend methanogenic processes has also been reported for some organic substrates, ${ }^{15,19-21}$ including lipidrich wastewaters, such as slaughterhouse wastewater and palm oil mill effluent. ${ }^{22,23}$ In those works oxygen was added in defined pulses or continuously, at variable concentrations, and reactors performance was monitored. However, information on the role and activity of facultative anaerobes as well as their possible metabolic interactions with strict anaerobes was never investigated.

We hypothesize that facultative anaerobic bacteria have an important role in the conversion of LCFA to methane in continuous high-rate bioreactors operated with microaeration. The experimental approach involved the operation of reactors under strict anaerobic and microaerophilic conditions. Facultative anaerobic microorganisms able to degrade LCFA were isolated and further studied in batch and continuous assays with diverse oxygen supply strategies.

\section{MATERIALS AND METHODS}

The methodology involved the operation of several bioreactors organized in three independent experiments as depicted in Figure 1.

Experiment 1: Influence of Microaeration in Oleate Biodegradation to Methane in Continuous Anaerobic Reactors. Two $1 \mathrm{~L}$ working volume upflow bioreactors were operated in continuous mode at mesophilic temperature (37 ${ }^{\circ} \mathrm{C}$ ). One of the reactors was operated under strict anaerobic conditions (anaerobic reactor, AnR in Figure 1a), guaranteed by adding sodium sulfide to the feed and by refilling the headspace of the feeding tank from a bag of nitrogen. The other reactor was fed from a tank that was open to the air (microaerophilic reactor, MaR in Figure 1a). Both systems were gently stirred twice a day during $5 \mathrm{~min}$.

Disrupted anaerobic granular sludge from a brewery wastewater treatment plant was used as inoculum, at a final concentration of $10 \mathrm{~g} \mathrm{~L}^{-1}$ in volatile solids (VS). Feeding was prepared by mixing sodium oleate $(\geq 82 \%$ as oleic acid, and the remaining composed of small percentages of other fatty acids, Riedel-de-Häen, Seelze, Germany) with tap water, and was supplemented with sodium bicarbonate $\left(3 \mathrm{~g} \mathrm{~L}^{-1}\right)$, micronutrients $\left(1 \mathrm{~mL} \mathrm{~L}^{-1}\right)$ and macronutrients $(0.6 \mathrm{~mL}$ per $\mathrm{g}$ of chemical oxygen demand, COD fed) according to Alves et al. (2001). ${ }^{24,25}$ The AnR feed was first boiled and cooled down under $\mathrm{N}_{2}$ flushing and then supplemented with $1 \mathrm{mmol} \mathrm{L}^{-1}$ of $\mathrm{Na}_{2} \mathrm{~S} \cdot 9 \mathrm{H}_{2} \mathrm{O}$.

The bioreactors operation was divided in two different periods according to the organic loading rate (OLR) applied. Oleate concentration in the feed (in COD) was $1 \mathrm{~g} \mathrm{~L}^{-1}$ during period I ( 52 days), and $4 \mathrm{~g} \mathrm{~L}^{-1}$ in COD in period II ( 11 days). The hydraulic retention time (HRT) was kept constant at 1 day in both periods. The reactors performance was monitored by measuring biogas production and methane content, $\mathrm{pH}$, oxidation-reduction potential (ORP), total COD in the influent, soluble+colloidal COD in the effluent, volatile fatty acids (VFA) and LCFA inside the reactor. Duplicate samples of well homogenized sludge were collected for assessing microbial community composition in both reactors after 27 and 62 days of operation.

At the end of period II, the reactors were kept in batch mode under mild agitation and after 23 days the methanogenic activity was assessed.

Methanogenic Activity Assays. A volume of $12.5 \mathrm{~mL}$ of a well homogenized sample was incubated in $25 \mathrm{~mL}$ batch vials, flushed with $\mathrm{N}_{2} / \mathrm{CO}_{2}(80: 20 \% \mathrm{v} / \mathrm{v})$. Ethanol $\left(30 \mathrm{mmol} \mathrm{L}^{-1}\right)$ was chosen as substrate because it is easy to biodegrade and helps to overcome mass transfer limitations of the LCFA accumulation in the sludge. ${ }^{11}$ The vials were incubated in the 
dark, at $37^{\circ} \mathrm{C}$, and stirred at $120 \mathrm{rpm}$. Pressure increase in the batch vials was measured using a hand-held pressure transducer, capable of measuring a pressure variation of 2 bar (0-202.6 $\mathrm{kPa}$ ) as described in Colleran et al. (1992). ${ }^{26}$ In each pressure measurement, biogas losses represent only about $0.2 \%$ of the total accumulated biogas. The methane content was periodically measured and the values of methane production were corrected for standard temperature and pressure (STP) conditions. The ethanol concentration was measured at the end of the assay by HPLC.

Experiment 2: Enrichment and Isolation of Facultative Anaerobic Bacteria from Continuous Bioreactors Fed with Oleic Acid. Enrichment Strategy. A continuous stirred tank reactor (CSTR) of $4.5 \mathrm{~L}$ was inoculated with an anaerobic sludge collected from the same source as the one utilized in Experiment 1 . The feeding was maintained in a tank open to air and prepared as previously described for Experiment 1 (MaR), with a sodium oleate concentration of $4 \mathrm{~g} \mathrm{~L}^{-1}$ in COD. The CSTR was operated with an initial HRT of $6 \mathrm{~h}$ to promote the washout of methanogens and other slow growing microorganisms and therefore enriching for the faster growing facultative anaerobic bacteria which could possibly be involved in oleate to palmitate conversion.

A thick biofilm was developed in the effluent discharging tube, hereafter designated as plug flow reactor (PFR, volume of $7.5 \mathrm{~mL}$ ) (Figure 1b). Samples from the PFR biofilm were collected periodically for LCFA quantification. Because significant accumulation of LCFA, other than oleate, was detected in the PFR, the operating strategy consisted in removing the biofilm from the PFR and use it to reinoculate the CSTR. The HRT was successively increased to 12,18 , and $24 \mathrm{~h}$ during the bioreactor operation (Table 3). For each HRT, after reaching the steady state, the procedure was repeated, that is, the biofilm from the PFR was reinoculated in the CSTR, LCFA content was analyzed and the bioreactor performance was monitored. Samples were collected from the CSTR and the PFR biofilm at days 22, 78, 107, and 119 of operation for DNA isolation and further microbial community characterization.

In order to verify the reproducibility of the results obtained, the described bioreactor operation (Experiment 2) was repeated in an independent experiment (trial 2) in which the CSTR+PFR system was inoculated with fresh sludge and operated exactly under the same conditions of Experiment 2 (trial 1), but only for the HRT of 6 and $12 \mathrm{~h}$. Samples from the PFR biofilm were collected for LCFA quantification and DNA extraction in order to study the microbial community composition.

The performance of the system (CSTR + PFR) was monitored by measuring: total COD in the influent; methane, $\mathrm{pH}, \mathrm{LCFA}$ and VFA in the CSTR; soluble+colloidal COD, LCFA and VFA in the effluent of the PFR.

Isolation of Facultative Anaerobic Bacteria. A biofilm sample $(100 \mu \mathrm{L})$ taken from the PFR, when the CSTR was operated at a HRT of $12 \mathrm{~h}$, was spread on $2 \%$ agar plates containing basal bicarbonate-buffered medium (without reducing agent $)^{27}$ and $1 \mathrm{mmol} \mathrm{L}^{-1}$ of sodium oleate $(\geq 99 \%$, Sigma-Aldrich, St. Louis, MO) as carbon source. The plates were incubated at $37{ }^{\circ} \mathrm{C}$ during 3 days, in aerobiosis. Single colonies were picked-up and transferred three times to new agar plates. Two different isolates with different colony morphologies (I1 and I2) could be obtained. Purity of the isolates was confirmed by phase contrast microscopic observations and the taxonomic identification was obtained by $16 \mathrm{~S}$ rRNA gene sequencing (Sanger sequencing).

Experiment 3: Degradation of Oleate by the Isolated Strains under Different ORP, Promoted by Diverse Oxygen Supply Strategies. Batch Assays. The ability of the isolates to metabolize oleate was studied in batch assays performed in closed serum bottles under four different redox conditions: strict anaerobic (supplemented with $1 \mathrm{mmol} \mathrm{L}^{-1}$ of $\mathrm{Na}_{2} \mathrm{~S}$, as reducing agent), anoxic (without the addition of reducing agent), microaerophilic and aerobic (headspace with 4 and $21 \%(\mathrm{v} / \mathrm{v})$ oxygen, respectively) (Figure 1c). All batch bottles contained bicarbonate-buffered mineral salt medium, 1 mmol L ${ }^{-1}$ sodium oleate, and a headspace initially composed of $\mathrm{N}_{2} / \mathrm{CO}_{2}(80: 20 \% \mathrm{v} / \mathrm{v}, 170 \mathrm{kPa})$, except for the aerobic assays. Air was added to the microaerophilic and aerobic assays with a pressure lock syringe (SGE, Ringwood, Australia) before autoclaving to obtain the required oxygen concentrations. Prior inoculation, isolates I1 and I 2 were first grown on liquid media supplemented with $0.5 \mathrm{~g} \mathrm{~L}^{-1}$ of glucose, under aerobic conditions, at $37{ }^{\circ} \mathrm{C}$ and at $100 \mathrm{rpm}$. Aliquots of the microbial cultures were collected during the exponential growth phase and used to inoculate the bottles $(10 \%(\mathrm{v} / \mathrm{v}))$. All tests were performed in duplicate and were incubated in the dark, at 37 ${ }^{\circ} \mathrm{C}$, with stirring at $100 \mathrm{rpm}$. For the aerobic and microaerophilic conditions, the test ended after 15 days, and for anoxic and anaerobic conditions took 1 month. In the end, the whole content of the bottles was lyophilized for further LCFA quantification. The capacity to degrade palmitate was also tested.

Continuous Bioreactors. Two CSTR of $0.25 \mathrm{~L}$ were inoculated with the isolates I1 and I 2 and were designated by R-I1 and R-I2, respectively. The inocula were prepared as described for the batch assays but using oleate $\left(1 \mathrm{mmol} \mathrm{L}^{-1}\right)$ as carbon source instead of glucose. At the beginning of the experiment, the biomass concentration inside the bioreactors was approximately $2 \mathrm{mg} \mathrm{L}^{-1}$ in organic nitrogen. The reactors were operated in continuous mode at mesophilic conditions $\left(37^{\circ} \mathrm{C}\right)$ during 22 days, with HRT of 1 day and with $1 \mathrm{~g} \mathrm{~L}^{-1}$ in COD of sodium oleate ( $\geq 82 \%$ as oleic acid, Riedel-de-Häen, Seelze, Germany). Feeding was prepared as described for MaR in Experiment 1, but in this case, it was autoclaved and the feeding tank was kept sterile by using a syringe filter in the air entrance (Figure 1c). The performance of the reactors was monitored by measuring $\mathrm{pH}, \mathrm{ORP}, \mathrm{COD}$ in the feed, and LCFA in the reactor. The morphology of the cells was examined by phase-contrast microscopy (Olympus-CX41, Olympus Corporation, Tokyo, Japan) and the viability of the isolates was tested periodically in agar plates, under the same conditions described for the isolation of the strains.

Analytical Methods. COD and organic nitrogen were determined spectrophotometrically using cuvette test kits (Hach-Lange GmbH, Düsseldorf, Germany) and a DR 2800 spectrophotometer (Hach-Lange $\mathrm{GmbH}$ ). Total and volatile solids were determined according to the Standard Methods. ${ }^{28}$ For soluble+colloidal COD and organic nitrogen, samples were previously centrifuged for $15 \mathrm{~min}$ at $15000 \mathrm{rpm}$. ORP was measured using a multiparameter analyzer C533 (Consort, Turnhout, Belgium) equipped with an ORP electrode D 223 (VWR, Radnor, PA). pH was measured with a Hanna (Woonsocket, RI) pH-meter. VFA were analyzed by high performance liquid chromatography (HPLC) (Jasco, Tokyo, Japan), using an Agilent Hi-Plex H column $(300 \times 7.7 \mathrm{~mm})$, maintained at $60{ }^{\circ} \mathrm{C}$ and with $\mathrm{UV}$ detection at $210 \mathrm{~nm}$. The 
Table 1. Operating Conditions and Performance Data in MaR and AnR: Organic Loading Rate Applied in COD to Both Reactors (OLR $\mathrm{COD}_{\mathrm{C}}$ ); Oxidation-Reduction Potential (ORP) and COD Removal Efficiency $\left(\mathrm{COD}_{\text {removal }}\right)$.

\begin{tabular}{|c|c|c|c|c|c|c|c|c|}
\hline \multirow[b]{2}{*}{ period } & \multirow[b]{2}{*}{$t / d$} & \multirow[b]{2}{*}{ mode } & \multicolumn{2}{|c|}{$\mathrm{OLR}_{\mathrm{COD}} / \mathrm{kg} \mathrm{m}^{-3} \mathrm{~d}^{-1}$} & \multicolumn{2}{|c|}{$\mathrm{ORP} / \mathrm{mV}$} & \multicolumn{2}{|c|}{$\mathrm{COD}_{\text {removal }} / \%$} \\
\hline & & & $\mathrm{MaR}$ & AnR & $\mathrm{MaR}$ & AnR & $\mathrm{MaR}$ & AnR \\
\hline I & $0-52$ & $\mathrm{C}$ & $1.4 \pm 0.6$ & $1.0 \pm 0.3$ & $-289 \pm 43$ & $-374 \pm 16$ & $96 \pm 1$ & $89 \pm 3$ \\
\hline II & $52-62$ & $\mathrm{C}$ & $2.9 \pm 0.5$ & $3.3 \pm 0.5$ & $-255 \pm 47$ & $-366 \pm 20$ & $84 \pm 4$ & $70 \pm 13$ \\
\hline
\end{tabular}

mobile phase was sulfuric acid $\left(5 \mathrm{mmol} \mathrm{L}{ }^{-1}\right)$ at $0.6 \mathrm{~mL} \mathrm{~min}^{-1}$ and crotonic acid was used as internal standard. Biogas production was measured with a Ritter MilliGas counter (Dr. Ing. Ritter Apparatebau GmbH, Bochum, Germany). Methane content of the biogas was analyzed by GC (Chrompack 9000) with a flame ionization detector (FID) and Carbowax $20 \mathrm{M}$ (2 $\mathrm{m} \times 2 \mathrm{~mm}, 80-120 \mathrm{mesh})$ column and using nitrogen $(30 \mathrm{~mL}$ $\left.\mathrm{min}^{-1}\right)$ as the carrier gas. The detector, injector, and oven temperatures were 35,110 , and $220{ }^{\circ} \mathrm{C}$, respectively. Free saturated and unsaturated LCFA from $\mathrm{C} 12$ to $\mathrm{C} 18$ were esterified with $\mathrm{HCl}$ :1-propanol at $100{ }^{\circ} \mathrm{C}$ for $3.5 \mathrm{~h}$, extracted with dichloromethane and quantified by GC-FID, as described by Neves et al. (2009). ${ }^{29}$ LCFA were separated using a Teknokroma TRB-WAX column $(30 \mathrm{~m} \times 0.25 \mathrm{~mm} \times 0.25 \mu \mathrm{m})$ with helium as the carrier gas, at $1 \mathrm{~mL} \mathrm{m^{-1 }}$. Temperatures of the injector and detector were 220 and $250{ }^{\circ} \mathrm{C}$, respectively. The initial oven temperature was $50{ }^{\circ} \mathrm{C}$, maintained for $2 \mathrm{~min}$, followed by a $10{ }^{\circ} \mathrm{C} \mathrm{min}^{-1} \mathrm{ramp}$ up to $225^{\circ} \mathrm{C}$, and finally isothermal conditions were maintained for $10 \mathrm{~min}$.

DNA Extraction and 16S rRNA Gene Sequencing. Samples of well-homogenized sludge were centrifuged (4000 $\mathrm{rpm}, 10 \mathrm{~min}$ at $4{ }^{\circ} \mathrm{C}$ ), the pellet was resuspended in $0.5 \mathrm{~mL}$ of PBS (phosphate-buffered saline) and preserved at $-20{ }^{\circ} \mathrm{C}$ until DNA isolation. Total genomic DNA was extracted using a FastDNA SPIN Kit for Soil (MP Biomedicals, Solon, OH) and purified by ethanol precipitation. DNA amplification, Illumina libraries preparation, amplicon sequencing (Illumina MiSeq, Inc. SanDiego, California) and bioinformatics analysis of the data were performed at Research and Testing Laboratory (RTL), Texas. Samples were amplified for sequencing using the universal primer pair, $515 \mathrm{f}$ and $806 \mathrm{r},{ }^{30}$ targeting the prokaryotic 16S rRNA gene. Details on the sequencing and bioinformatics data analysis can be found elsewhere. ${ }^{31}$ The FASTQ files were submitted in the ENA (European Nucleotide Archive), being available in the following link http://www.ebi.ac.uk/ena/data/ view/PRJEB11469. Nucleotide sequences from Experiment 1 are identified with accession numbers ERS937154 to ERS937157 and sequences from Experiment 2 with the accession numbers ERS1487522 to ERS1487524 and ERS1505407 for trial 1 and ERS2319672 to ERS2319677 for trial 2.

For the taxonomic identification of the isolates, a single colony was suspended in $50 \mu \mathrm{L}$ of TE buffer. DNA was isolated after exposing the colonies at $95{ }^{\circ} \mathrm{C}$ during $10 \mathrm{~min}$ to promote cell lysis. The bacterial $16 \mathrm{~S}$ rRNA genes were amplified by PCR (polymerase chain reaction) with a Taq DNA polymerase (EP0402, ThermoScientific, San Diego, CA) and universal primers $27 \mathrm{f}$ and $1492 \mathrm{r}$ targeting the bacterial $16 \mathrm{~S}$ rRNA gene, as detailed elsewhere. ${ }^{32,33}$ Sanger sequencing was performed by Macrogen (Amsterdam, The Netherlands). The sequences were checked and cleaned using BioEdit (http://www.mbio. ncsu.edu/bioedit/bioedit.html). Identification of $16 \mathrm{~S}$ rRNA gene sequences was obtained by local alignment with NCBI nucleotide database using BLAST (http://blast.ncbi.nlm.nih. gov/Blast.cgi). Isolates sequences are identified with accession numbers LT903717-LT903718 in ENA (www.ebi.ac.uk/ena/ data/view/LT903717-LT903718).

For DGGE analysis, PCR products were generated using bacterial 16S rRNA gene primers 968f-GC and 1401r. ${ }^{34} \mathrm{~A}$ description of PCR programs and primers sequences was described by Sousa et al. (2007). ${ }^{32}$ All primers used were synthesized commercially by Invitrogen (Life Technologies, Porto, Portugal). Size and yield of PCR products were estimated using a $1 \mathrm{~kb}$ extended DNA ladder (ThermoScientific, San Diego, CA) and a green safe staining via $1 \%(\mathrm{w} / \mathrm{v})$ agarose gel electrophoresis. DGGE analysis of the amplicons was performed as previously described by Zoetendal et al. (2001), ${ }^{35}$ using the Dcode system (Bio-Rad, Hercules, CA) with $8 \%(\mathrm{v} / \mathrm{v})$ polyacrylamide gels and a denaturant gradient of $30-60 \%$. A 100\% denaturing solution was defined as $7 \mathrm{~mol} \mathrm{~L}^{-1}$ urea and $40 \%$ formamide. Electrophoresis was performed for 16 $\mathrm{h}$ at $85 \mathrm{~V}$ in a $0.5 \times \mathrm{TAE}$ buffer at $60{ }^{\circ} \mathrm{C}$. DGGE gels were stained with $\mathrm{AgNO}_{3}$ as described Sanguinetti et al. $(1994)^{36}$ and scanned at $400 \mathrm{dpi}$.

Microscopy Inspection. PFR segments were cut with a scalpel, placed in OCT compound and immediately frozen with liquid nitrogen. Preserved samples were kept at $-20{ }^{\circ} \mathrm{C}$ until being sliced in $50 \mu \mathrm{m}$ thick sections with a cryomicrotome (Leica Microtome 1900). Before the staining, all the samples were fixed directly in the slides with $4 \%$ formaldehyde solution (freshly prepared in PBS), in order to maintain the morphological integrity of the cells. The slides were washed with PBS and then double stained with DAPI $\left(0.1 \mathrm{~g} \mathrm{~L}^{-1}\right)$ and Nile Red $\left(10 \mathrm{mg} \mathrm{L}^{-1}\right)$. Both stains were incubated during 10 min at room temperature and the slides were washed with PBS after incubation with each one of the staining compounds. Biofilm images were acquired in a confocal scanning laser microscope (Olympus BX61, model FluoView 1000). DAPI (Sigma, Darmstadt, Germany) was used to the detection of cells, as it links to DNA (laser excitation line $405 \mathrm{~nm}$ and emissions filters BA 430-470, blue channel) and Nile Red (Sigma, Darmstadt, Germany) to stain hydrophobic compounds (laser excitation line 559nm and emissions filters BA 575-675, red channel). Images were acquired with the program FV10-Ver4.1.1.5 (Olympus, Tokyo, Japan).

Statistical Analysis. To investigate if bioreactors performance were significantly different, Student's $t$ test were applied. In experiment 1 , the set of COD values obtained for each reactor and in each period were compared. In experiment 1 , in period I $n=14$ and in period II $n=4$ ( $n$ represents the number of samples analyzed). In experiment 2, palmitate-to-total LCFA percentage in the samples collected in trial 1 and trial 2 were initially compared, to determine if the two trials were significantly different or not, with the objective of determine the reproducibility of the trials. After that, this set of values from trial 1 and trial 2 were used to compare palmitate-to-total percentage between periods. Canonical correspondence analysis (CCA) was performed to relate operational parameters (HRT and palmitate percentage in the PFR-biofilm) with the microbial community composition, using the operational 
taxonomic units (OTU) with more than $1 \%$ of relative abundance. CCA was done in Excel using the XLSTAT statistical software. All levels of significance were defined at $P \leq$ 0.05 .

\section{RESULTS}

Experiment 1: Influence of Microaeration in Oleate Biodegradation to Methane in Continuous Anaerobic Bioreactors. Oxygen concentrations in bioreactors AnR and MaR (Experiment 1) were below the probe detection limit $\left(0.01 \mathrm{mg} \mathrm{L}^{-1}\right)$, but the ORP differed and was a clear indicator of the different operating conditions applied in both reactors. ORP values were approximately $100 \mathrm{mV}$ higher in MaR than in AnR (Table 1). The ORP was also measured in the feeding tanks of both reactors, which were about -80 and $-300 \mathrm{mV}$ in $\mathrm{MaR}$ and AnR, respectively (Supporting Information (SI) Table S1). COD removal efficiency during period I was higher $(p<0.001)$ in MaR than in AnR, but in period II no significant differences were observed $(p>0.05)$ (Table 1$)$. With the increase of the OLR (period II), the reactors content became whitish, due to the accumulation of LCFA, and the biogas production decreased (Figure $2 \mathrm{c}$ ). In the $\mathrm{MaR}$ a floating layer of LCFA-entrapped sludge was formed but the same did not occur in the AnR (SI Figure S1).

Palmitate $(\mathrm{C} 16: 0)$ and oleate $(\mathrm{C} 18: 1)$ represented more than $85 \%$ of the total LCFA detected during the reactors operation. During period I, palmitate concentrations reached maximum values of $850 \mathrm{mg} \mathrm{L}^{-1}$ and $1100 \mathrm{mg} \mathrm{L}^{-1}$ in COD in the $\mathrm{MaR}$ and $\mathrm{AnR}$, respectively, while lower oleate-COD concentrations, below $400 \mathrm{mg} \mathrm{L}^{-1}$, were detected in both

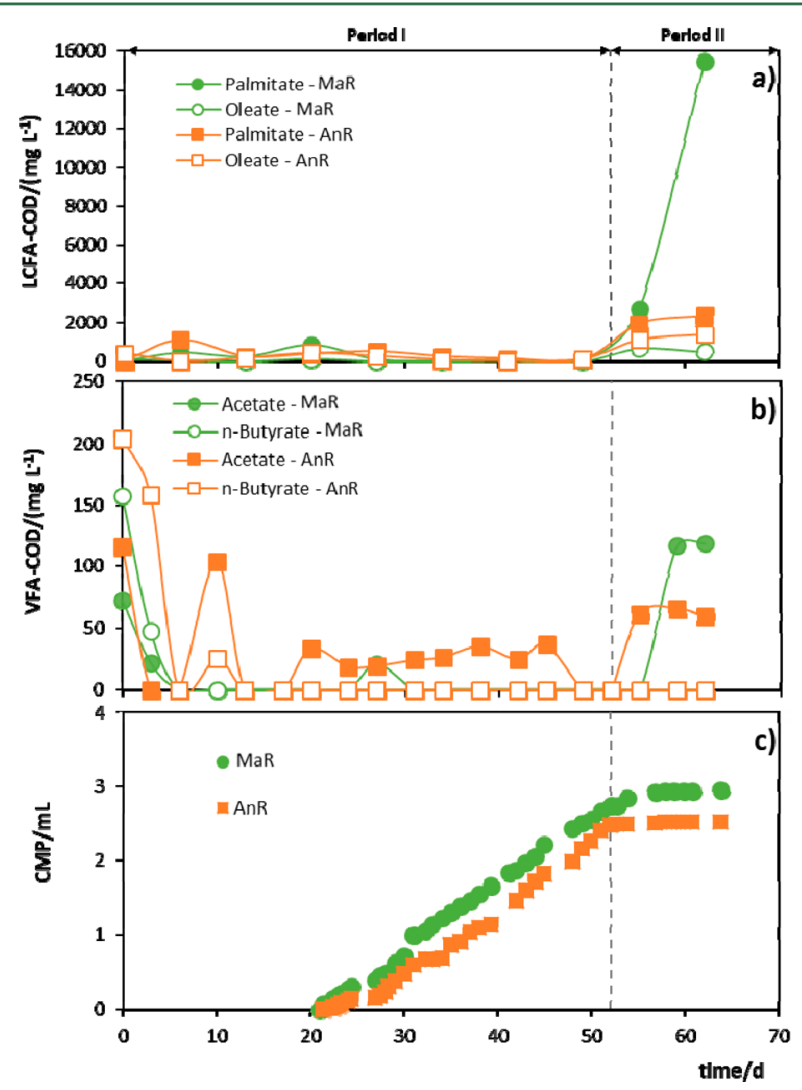

Figure 2. LCFA inside the reactor (a), VFA (b) and cumulative methane production (CMP) (c) during periods I and II in the reactors $\mathrm{MaR}$ and AnR. reactors (Figure 2a). Throughout period II, with the increase of the OLR, palmitate concentration inside the MaR accumulated up to $15500 \mathrm{mg} \mathrm{L}^{-1}$ in COD. Oleate $\left(474 \mathrm{mg} \mathrm{L}^{-1}\right.$ in COD), stearate $\left(915 \mathrm{mg} \mathrm{L}^{-1}\right.$ in COD) and myristate $\left(686 \mathrm{mg} \mathrm{L}^{-1}\right.$ in COD) were also detected. In the AnR, palmitate concentration also increased but only up to $2351 \mathrm{mg} \mathrm{L}^{-1}$ and oleate reached $1382 \mathrm{mg} \mathrm{L}^{-1}$, in COD (Figure 2a). $\mathrm{pH}$ varied in both reactors from 6.7 to 8.5 .

Acetate and $n$-butyrate were the only VFA detected during the experiment (Figure $2 \mathrm{~b}$ ). In $\mathrm{MaR}$, acetate accumulated mainly during period II and reached a maximum value of 120 $\mathrm{mg} \mathrm{L}^{-1}$ in COD. In the same period, acetate concentration (in COD) increased up to $60 \mathrm{mg} \mathrm{L}^{-1}$ in AnR.

Methane production ceased completely in both reactors in period II. Subsequently, the feeding was stopped to allow the degradation of the accumulated fatty acids. After 23 days of batch operation, palmitate concentration in MaR decreased by 91\%, whereas in AnR no measurable difference was detected. At this point, sludge was collected from both reactors in order to assess the specific methanogenic activity in the presence of ethanol, which gives information on the activity of different trophic microbial groups, the bacteria that convert ethanol to acetate and hydrogen, and the methanogens that produce methane from those intermediary products.

The sludge from MaR produced $37 \mathrm{mmol} \mathrm{L}^{-1}$ of methane after 11 days of incubation, which corresponds approximately to the theoretical value expected if all the ethanol was converted to methane (SI Figure S2). The complete degradation of ethanol was also confirmed by its absence at the end of the assay. On the other hand, no methane was produced by the sludge collected from AnR, though $80 \%$ of the ethanol was converted to acetate $\left(6.5 \mathrm{mmol} \mathrm{L}^{-1}\right.$ of ethanol and $28 \mathrm{mmol} \mathrm{L}^{-1}$ of acetate were detected at the end of the activity test), showing that the methanogenic activity of the sludge was inhibited but not the acetogenic activity.

The microbial community composition was assessed in both reactors (Table 2). In period I, methanogenic communities were composed by Methanobacterium and Methanosaeta in both reactors, with the predominance of Methanobacterium (36\% of abundance) in the AnR. In the MaR these genera were present in equal relative percentages (approximately 10\%). The bacterial community in AnR was composed by Syntrophomonas, Syntrophobacter and bacteria from the orders Synergistales, Anaerolineales, Cytophagales, and Syntrophobacterales. In MaR facultative anaerobic bacteria accounted for $23 \%$ of the total sequences retrieved (17\% Stenotrophomonas and 6\% Deftia). With the increase of OLR, the relative abundance of Archaea decreased in both reactors. In AnR Syntrophomonas and Syntrophobacter became less abundant as well, and the relative abundance of facultative anaerobic bacteria (e.g., Pseudomonas, Stenotrophomonas, and Aeromonas) increased to $21 \%$.

Experiment 2: Enrichment and Isolation of Facultative Anaerobic Bacteria from Continuous Bioreactors Fed with Oleic Acid. Previous experiments from Cavaleiro et al. $(2016)^{12}$ showed that oleate conversion to palmitate can occur independently of methanogenesis and that facultative anaerobic bacteria are enriched under such conditions. In this work, we applied high organic loading rates and low hydraulic retention times (Table 3) to selectively washout the microorganisms with slower growth rates (including methanogens) and simultaneously to enrich for microorganisms capable of performing oleate to palmitate conversion. Interestingly it was observed that the effluent washed out from the CSTR was partially 
Table 2. Taxonomic Identification of the Microbial Reads at the Genus Level (at > 1\% Relative Abundance), in Reactors MaR and AnR at Days 27 (Period I) And 62 (Period II) Of Operation ${ }^{a}$

\begin{tabular}{|c|c|c|c|c|c|c|}
\hline phylum & order & genus & MaR_27d & MaR_62d & AnR_27d & AnR_62d \\
\hline Proteobacteria & Xanthomonadales & Stenotrophomonas & 17 & 4 & $<1$ & 7 \\
\hline Unclassified Bacteria & & & 16 & 2 & 20 & 3 \\
\hline Euryarchaeota & Methanosarcinales & Methanosaeta & 10 & 3 & 11 & 5 \\
\hline Euryarchaeota & Methanobacteriales & Methanobacterium & 9 & 9 & 36 & 14 \\
\hline Proteobacteria & Burkholderiales & Delftia & 6 & 2 & $<1$ & 2 \\
\hline Proteobacteria & Syntrophobacterales & & 4 & $<1$ & 2 & $<1$ \\
\hline Chloroflexi & Anaerolineales & & 4 & $<1$ & 3 & $<1$ \\
\hline Synergistetes & Synergistales & & 3 & 1 & 5 & 1 \\
\hline Thermotogae & & & 3 & $<1$ & $<1$ & $<1$ \\
\hline Planctomycetes & & & 2 & $<1$ & $<1$ & $<1$ \\
\hline Bacteroidetes & Cytophagales & Cytophaga & 2 & 2 & 2 & 2 \\
\hline Proteobacteria & Syntrophobacterales & Syntrophobacter & 2 & $<1$ & 3 & $<1$ \\
\hline Chloroflexi & & & 2 & $<1$ & 3 & $<1$ \\
\hline Firmicutes & & & 2 & 3 & 1 & 4 \\
\hline Spirochaetes & & & 1 & $<1$ & 2 & 1 \\
\hline Proteobacteria & Rhodocyclales & Dechloromonas & 1 & $<1$ & $<1$ & $<1$ \\
\hline Thermotogae & Thermotogales & Mesotoga & 1 & $<1$ & $<1$ & nd \\
\hline Firmicutes & Clostridiales & Syntrophomonas & 1 & $<1$ & 2 & $<1$ \\
\hline Bacteroidetes & Bacteroidales & Bacteroides & 1 & 3 & $<1$ & $<1$ \\
\hline Proteobacteria & Burkholderiales & Leptothrix & $<1$ & 25 & nd & nd \\
\hline Proteobacteria & Burkholderiales & Comamonas & $<1$ & 10 & $<1$ & $<1$ \\
\hline Proteobacteria & Rhodocyclales & Azospira & $<1$ & 8 & nd & 17 \\
\hline Proteobacteria & Pseudomonadales & Pseudomonas & $<1$ & 3 & $<1$ & 9 \\
\hline Proteobacteria & Caulobacterales & Caulobacter & $<1$ & 3 & $<1$ & $<1$ \\
\hline Synergistetes & Synergistales & Aminiphilus & $<1$ & 2 & $<1$ & 7 \\
\hline Proteobacteria & Burkholderiales & Acidovorax & $<1$ & 2 & $<1$ & $<1$ \\
\hline Synergistetes & Synergistales & Aminivibrio & $<1$ & 1 & $<1$ & $<1$ \\
\hline Proteobacteria & Xanthomonadales & Luteimonas & nd & 1 & nd & nd \\
\hline Bacteroidetes & Sphingobacteriales & & $<1$ & 2 & $<1$ & nd \\
\hline Proteobacteria & Aeromonadales & Aeromonas & nd & nd & nd & 5 \\
\hline Proteobacteria & Neisseriales & Microvirgula & nd & $<1$ & $<1$ & 3 \\
\hline Proteobacteria & Desulfovibrionales & Desulfovibrio & $<1$ & $<1$ & $<1$ & 2 \\
\hline Bacteroidetes & Flavobacteriales & Chryseobacterium & $<1$ & $<1$ & $<1$ & 2 \\
\hline Proteobacteria & Caulobacterales & Brevundimonas & $<1$ & $<1$ & $<1$ & 2 \\
\hline
\end{tabular}

Table 3. Operating Conditions and Performance Date in the CSTR and PFR: Organic Loading Rate Applied in COD to the CSTR (OLR-CSTR); Hydraulic Retention Time in CSTR (HRT-CSTR) and in the PFR (HRT-PFR); LCFA Content in the PFR Biofilm.

\begin{tabular}{|c|c|c|c|c|c|c|c|c|}
\hline period & trial & OLR-CSTR/ $\mathrm{kg}$ COD $\mathrm{m}^{-3} \mathrm{~d}^{-1}$ & HRT-CSTR/ h & HRT-PFR/ h & time/d & oleate $/ \%$ & palmitate $/ \%$ & others $/ \%$ \\
\hline \multirow[t]{5}{*}{ I } & 1 & $13.3 \pm 0.6$ & $6.3 \pm 0.2$ & $0.01 \pm 0$ & 22 & 31 & 51 & 18 \\
\hline & & & & & 35 & 4 & 82 & 14 \\
\hline & 2 & $12.8 \pm 2.6$ & $6.4 \pm 0.8$ & $0.01 \pm 0$ & 38 & 24 & 67 & 9 \\
\hline & & & & & 45 & 22 & 69 & 9 \\
\hline & & & & & 53 & 22 & 69 & 9 \\
\hline \multirow[t]{6}{*}{ II } & 1 & $6.4 \pm 0.3$ & $12.7 \pm 0.2$ & $0.02 \pm 0$ & 43 & 47 & 33 & 20 \\
\hline & & & & & 53 & 25 & 58 & 17 \\
\hline & & & & & 78 & 15 & 72 & 13 \\
\hline & 2 & $5.8 \pm 1.2$ & $12.7 \pm 0.3$ & $0.02 \pm 0$ & 60 & 49 & 44 & 7 \\
\hline & & & & & 68 & 52 & 41 & 7 \\
\hline & & & & & 76 & 28 & 64 & 8 \\
\hline III & 1 & $4.2 \pm 0.8$ & $17.5 \pm 0.5$ & $0.03 \pm 0$ & 87 & 59 & 18 & 23 \\
\hline \multirow[t]{2}{*}{ IV } & 1 & $3.0 \pm 0.9$ & $23.5 \pm 0.6$ & $0.04 \pm 0$ & 119 & 56 & 23 & 21 \\
\hline & & & & & 125 & 84 & 8 & 8 \\
\hline
\end{tabular}

retained in a thick biofilm formed in the discharge tube (submerged) that acted as a PFR-biofilm reactor having a very low HRT of just a few minutes. Thus, during this bioreactor operation two different systems were distinguished and studied (CSTR and PFR, Figure 1b), presenting different reaction profiles and different microbial community composition. 
Table 4. Taxonomic Identification of the Microbial Reads at the Genus Level (At $>1 \%$ Abundance), during the Periods I to IV of the PFR Operation ${ }^{a}$

\begin{tabular}{|c|c|c|c|c|c|c|c|c|c|c|}
\hline genus/\% & $\mathrm{P}(\mathrm{I})$ trial1 $_{22 \mathrm{~d}}$ & $\underset{38 \mathrm{I})_{\text {trial2 }}}{\mathrm{d}}$ & $\mathrm{P}_{45 \mathrm{I})_{\text {trial2 }}}$ & $\left.\mathrm{P}(\mathrm{I})_{53}\right)_{\text {trial }}$ & $\mathrm{P}(\mathrm{II})_{7 \overline{8} \mathrm{~d}}{ }_{\text {triall }}$ & $\mathrm{P}^{\mathrm{P}(\mathrm{II}) \text { trial2 }}$ & $\mathrm{P}_{68 \mathrm{dI} \mathrm{d}^{\text {trial2 }}}$ & $\mathrm{P}(\mathrm{II})_{7 \overline{6} \mathrm{~d}}$ trial2 & $\begin{array}{c}\mathrm{P}(\mathrm{III}) \text { trial1 } \\
107 \mathrm{~d}\end{array}$ & $\begin{array}{c}\mathrm{P}(\mathrm{IV}) \text { trial1 } \\
119 \mathrm{~d}\end{array}$ \\
\hline Pseudomonas & 42 & 7 & 14 & 16 & 58 & 11 & 6 & 16 & 2 & nd \\
\hline Acinetobacter & 20 & 36 & 34 & 19 & nd & 15 & 25 & 24 & $<1$ & 1 \\
\hline Unclassified Bacteria & 21 & 3 & 4 & 6 & 3 & 4 & 1 & 8 & $<1$ & $<1$ \\
\hline Azoarcus & 10 & $<1$ & $<1$ & nd & 10 & nd & nd & nd & 8 & $<1$ \\
\hline Aeromonas & 5 & $<1$ & $<1$ & $<1$ & 3 & $<1$ & $<1$ & $<1$ & $<1$ & $<1$ \\
\hline Delftia & $<1$ & 16 & 3 & 18 & 5 & 19 & 29 & 12 & 3 & $<1$ \\
\hline Staphylococcus & nd & nd & nd & nd & 4 & nd & nd & nd & $<1$ & $<1$ \\
\hline Comamonas & $<1$ & $<1$ & $<1$ & $<1$ & 2 & $<1$ & $<1$ & $<1$ & $<1$ & $<1$ \\
\hline Parabacteroides & nd & $<1$ & $<1$ & $<1$ & 2 & $<2$ & nd & $<2$ & nd & $<1$ \\
\hline Ochrobactrum & nd & 1 & $<1$ & $<1$ & 1 & 1 & $<1$ & $<1$ & 46 & 4 \\
\hline Aquamicrobium & nd & $<1$ & $<1$ & $<1$ & $<1$ & $<1$ & nd & $<1$ & 17 & 3 \\
\hline Microvirgula & nd & 11 & 3 & 4 & nd & 16 & 5 & 4 & 5 & 65 \\
\hline Bosea & nd & 3 & 6 & 3 & nd & 2 & 1 & $<1$ & 5 & 5 \\
\hline Escherichia & nd & nd & nd & nd & nd & nd & nd & nd & 1 & $<1$ \\
\hline Stenotrophomonas & $<1$ & 13 & 12 & 13 & $<1$ & 12 & 10 & 12 & 10 & 10 \\
\hline Proteocatella & nd & nd & nd & nd & nd & nd & nd & nd & $<1$ & 4 \\
\hline Agrobacterium & nd & nd & nd & nd & nd & nd & nd & nd & $<1$ & 2 \\
\hline Chryseobacterium & nd & 3 & 5 & 3 & nd & 5 & 6 & 1 & $<1$ & $<1$ \\
\hline Dysgonomonas & $<1$ & 2 & 3 & 6 & $<1$ & 4 & 4 & 6 & $<1$ & $<1$ \\
\hline Variovorax & nd & 1 & 2 & 1 & nd & $<1$ & $<1$ & $<1$ & nd & nd \\
\hline Sphingopyxis & nd & $<1$ & 2 & $<1$ & nd & $<1$ & $<1$ & $<1$ & nd & nd \\
\hline Camelimonas & nd & nd & nd & nd & nd & nd & 3 & 1 & nd & nd \\
\hline Parachlamydia & nd & nd & nd & nd & nd & $<1$ & 2 & 1 & nd & nd \\
\hline Arcobacter & nd & $<1$ & $<1$ & 2 & nd & $<1$ & $<1$ & $<1$ & nd & nd \\
\hline Azospira & nd & $<1$ & $<1$ & 1 & nd & $<1$ & $<1$ & $<1$ & nd & $<1$ \\
\hline Pleomorphomonas & nd & $<1$ & $<1$ & $<1$ & nd & 1 & $<1$ & 2 & nd & $<1$ \\
\hline
\end{tabular}

The LCFA profiles in the effluent from the CSTR and from the PFR were similar, with oleate as the main fatty acid quantified (SI Figure S3). VFA and methane were not detected during the experiment and $\mathrm{pH}$ varied from 7 to 9 in the CSTR. Biofilm formation was observed in the PFR in all the operational periods, which contained both hydrophobic compounds and cells, as visualized by confocal microscopy (SI Figure S4). In periods I and II, palmitate was the main LCFA detected in the biofilm, varying between 50 and $80 \%$ (except at day 43, immediately after increasing the HRT).

In a new independent experiment (trial 2 in Periods I and II) palmitate percentage in the biofilm was statistically equal $(p>$ 0.05 ) to the observed in trial 1 in the same periods, showing the consistency and robustness of the results. In periods III and IV (trial 1$)$, a shift $(p<0.05)$ was observed and oleate became the dominant LCFA in the biofilm, reaching a value of $84 \%$, which corresponds to the percentage of oleate in the feeding (Table 3).

The high amount of palmitate present in the biofilm during period I and II suggests the presence of bacteria that convert oleate to palmitate. These microbial communities were mainly composed by facultative anaerobic bacteria (Table 4). In trial 1 , Pseudomonas was the predominant genus, representing $42 \%$ and $58 \%$ of the microorganisms detected in periods I and II, respectively (Table 4). It was also a predominant genus in trial 2 , representing up to $16 \%$ of the total microbial community, together with other facultative anaerobic bacteria assigned to genera Acinetobacter (up to 36\%), Delftia (up to 29\%), and Stenotrophomonas (up to 13\%) (Table 4). The difference between the trials is not surprising, as a different inoculum was used, although from a similar source. In periods III and IV, where longer HRTs were applied, the relative abundance of facultative anaerobes decreased and aerobic genus such as Ochrobactrum and Microvirgula became predominant. Interestingly, in these periods oleate was the main LCFA detected in the biofilm (Table 3).

CCA analysis using all data obtained in trials 1 and 2 demonstrated that the microbial genera are correlated to the tested variables, that is, palmitate-to-total LCFA percentage and HRT $(p<0.05)$. The abundance of facultative anaerobes, in particular of Pseudomonas sp, is highly correlated with the accumulation of palmitate (Figure 3).

Two Pseudomonas strains (I1 and I2) were isolated from the biofilm collected from PFR in period II and exhibit two distinct colony types. The colony formed by I1 was transparent and had a dispersive like shape; the colony formed by $\mathrm{I} 2$ has a circular raised shape and smooth appearance (SI Figure S5a). Both isolates were rod-shaped when observed by phase contrast microscopy (SI Figure S5b,c). DGGE analysis confirmed the presence of I1 and I2 in CSTR and in PFR (SI Figure S6). Bands corresponding to I1 and I2 were rather intense, when compared with remaining bands, confirming their high relative abundance in the bioreactors.

Isolates I1 and I 2 shared $98.2 \%$ similarity of the $16 \mathrm{~S}$ rRNA gene, and presented $99 \%$ of identity with several species of Pseudomonas (data not shown). In general, closely related species of bacteria, like the ones belonging to Pseudomonas genus, cannot be differentiated based on the 16S rRNA gene, but can be grouped as suggested by Gomila et al. (2015). ${ }^{37}$ 


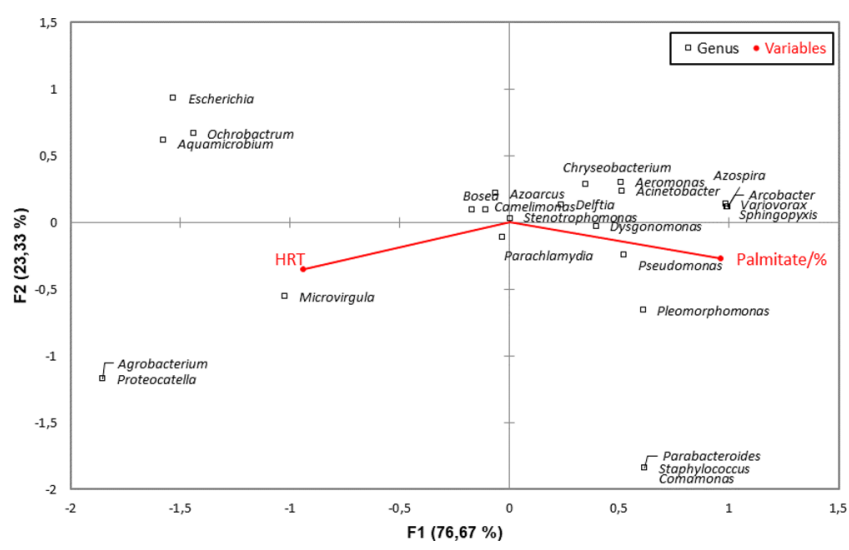

Figure 3. Canonical correspondence analysis (CCA) between microbial community composition and environmental variables (palmitate and HRT).

Such analysis indicates that strain I1 and I2 are affiliated within the $P$. oleovorans and P. stutzeri group, respectively.

Experiment 3: Degradation of Oleate by the Isolated Strains under Different ORP, Promoted by Diverse Oxygen Supply Strategies. Under aerobic conditions and during an incubation of 15 days in batch, strain I1 was able to degrade around $84 \%$ of the initial oleate added, while strain I2 was only able to degrade $36 \%$. Palmitate was also completely degraded by both isolates. Under microaerophilic conditions (in the presence of approximately $4 \% \mathrm{O}_{2}$ ) both isolates degraded oleate up to $24 \%$ in 15 days. Oleate degradation was not observed in the tests where anoxic and anaerobic conditions were applied, at least during 30 days of incubation (SI Table S2). No intermediary compounds, such as other LCFA or VFA, were detected in the assays.

In continuous bioreactors inoculated with strains I1 and I2, oleate concentration decreased till a minimum value of around $100 \mathrm{mg} \mathrm{L}^{-1}$ in COD, and palmitate concentration was also similar in both reactors and was always lower than $40 \mathrm{mg} \mathrm{L}^{-1}$ in COD (SI Figure S7). Other LCFA were detected in negligible amounts $\left(<20 \mathrm{mg} \mathrm{L}^{-1} \mathrm{COD}\right)$. Both reactors presented a similar ORP with an average value of $118 \pm 30 \mathrm{mV}$ and $127 \pm 18 \mathrm{mV}$, for R-I1 and R-I2 respectively.

\section{DISCUSSION}

It is well-known that bacteria belonging to the genus Syntrophomonas perform LCFA degradation in syntrophy with methanogens. ${ }^{1}$ However, in high-rate continuous bioreactors inoculated with complex microbial communities, syntrophic fatty acid degrading bacteria are generally present in low relative abundance, that is, $0.2-3 \%{ }^{1,38}$ Accumulation of palmitate from oleate has been reported at organic loads higher than $3 \mathrm{~g} \mathrm{~L}^{-1} \mathrm{~d}^{-1}$ as oleate (in COD). ${ }^{3}$ However, palmitate was never detected in defined syntrophic cocultures, for example of Syntrophomonas zehnderi and Methanobacterium formicicum, growing on oleate. ${ }^{12}$

Microbial community analysis of sludge degrading LCFA showed the presence of facultative anaerobic bacteria in continuous methanogenic reactors. ${ }^{12,13}$ Currently, it is not known if these bacteria are involved in LCFA degradation, and if they are dependent on the presence of oxygen, or not.

Here, we investigated the possible effect of microaeration to trigger palmitate formation from oleate-based wastewater. This strategy lead to an increase in the ORP from $-350 \mathrm{mV}$ (control, under strict anaerobic conditions, AnR) to $-250 \mathrm{mV}$ (MaR) although oxygen was not detected in the bulk medium. Facultative anaerobic bacteria were abundant in MaR (Table $2)$, possibly helping to create and maintain local oxygendepleted conditions. In AnR, the community was mainly composed of methanogens and other strict anaerobes, including known syntrophic bacteria (Table 2). In reactor MaR, LCFA removal (assessed indirectly by COD measurements) may have occurred anaerobically with conversion to methane, or aerobically to $\mathrm{CO}_{2}$. However, from the cumulative methane production (Figure 2c), it is clear that similar amounts were obtained and even a slightly higher accumulation was observed in the microaerophilic reactor. This shows that COD was removed for the production of methane and not by an aerobic pathway, suggesting a cooperation rather than competition between aerobic and anaerobic metabolism.

When the OLR was increased, the methane production ceased in both reactors and LCFA accumulated. Low methane yields associated to LCFA accumulation in continuous bioreactors was described previously, ${ }^{11,39}$ and subsequent degradation of biomass-associated LCFA to methane has been demonstrated by suppressing the feeding and operating the reactor in batch mode for a certain period of time. ${ }^{8}$ In this study, palmitate accumulated inside the reactor up to 7 times more in MaR than in AnR. Conversely, oleate concentration inside AnR was about 3 times higher than in MaR. After suppressing the feed to both reactors, the microbial community from MaR was able to degrade the LCFA accumulated in the reactor, but this was not the case in $\mathrm{AnR}$, where the accumulation of LCFA was persistent. In addition, only the MaR sludge exhibited specific methanogenic activity. Oleate is reported to be more toxic than palmitate toward methanogens, in pure or in mixed cultures ${ }^{11,40-42}$ and maybe this is the cause of the decrease in the methanogens' relative abundance and activity in AnR.

Information on LCFA toxicity and inhibition is controversial. In some studies, LCFA exerted a permanent and irreversible toxic effect toward methanogenic communities, ${ }^{43,44}$ while in other studies this was not the case. ${ }^{25,45}$ Differences in the operational methodologies, specifically the feeding procedures in lab-scale reactors are usually not described in detail, and this may be the reason for the different conclusions previously reported. Here we show that, indeed, having a strict anaerobic feed or a feeding tank open to air, resulted in a different ORP, different microbial community profiles and a different behavior relative to oleate conversion. Interestingly, open to air feeding promoted the transformation of oleate to palmitate, avoiding a long-term methanogenic inhibition as observed in AnR. From an applied point of view this information is of very important, since at industrial scale the feeding tanks/pipelines are not kept under strict anaerobic conditions and small amounts of oxygen can be introduced to the system.

The involvement of facultative anaerobes in oleate conversion to methane was further investigated. By applying high hydraulic loading rates (Experiment 2) it was possible to enrich for facultative anaerobic microorganisms, which formed a thick palmitate-rich biofilm in a plug flow reactor fed with oleate. The abundance of facultative anaerobes, in particular of Pseudomonas spp., was highly correlated with the accumulation of palmitate, strongly suggesting that these microorganisms are involved in palmitate formation from oleate. This is in accordance with the predominance of these bacteria in bioreactors where oleate to palmitate conversion occurred. ${ }^{12,13}$ 
It is noteworthy to highlight that it was required to operate the PFR at extremely low and unusual hydraulic retention times in the range of $0.01-0.04 \mathrm{~h}$, to establish the microbial community involved in the accumulation of palmitate from oleate degradation.

The two Pseudomonas strains isolated from the biofilm were able to biodegrade oleate in batch assays, under aerobic and microaerophilic conditions, but not in the absence of oxygen. Oleate was consumed according to the amount of oxygen supplied and no intermediates were detected. The isolates were further tested in continuous bioreactors, to simulate the continuous input of very low levels of oxygen where oleate degradation occurred again without palmitate detection. Since oxygen input was not quantifiable, the mass balance could not be determined in this case, but oleate was converted, and the viability of cells was confirmed. We cannot exclude that bacteria other than Pseudomonas are involved in oleate conversion to palmitate. However, the fact that palmitate was not detected in the tested conditions does not exclude the potential involvement of these bacteria in oleate conversion to palmitate, since our isolates were grown in planktonic form in pure culture, while palmitate formation was associated with a biofilm composed of several microorganisms. There are several examples of microorganisms which have different functions when growing within microbial communities or in pure cultures, and this may be the case of our Pseudomonas isolates. Moreover, it is known that some Pseudomonas spp. growing in biofilms have a different physiology than when growing as planktonic cells. ${ }^{46}$ For example, when Heffernan et al. $(2009)^{47}$ compared fluoroacetate degradation by $P$. fluorescens grown in biofilm, and in planktonic forms, differences were observed in the cells' performance mainly associated with the accumulation of an intermediate metabolite (glycolate) in the biofilm. Studies in batch assays with defined cultures or cocultures are important to add evidence about possible mechanisms and metabolic traits taking place in microbial communities, but do not inform about interactions and relevance of potential multiple pathways occurring simultaneously in these complex systems.

In summary, microaeration promoted a slightly higher ORP conditions $(-250 \mathrm{mV}$ vs $-350 \mathrm{mV})$, that stimulated the presence of facultative anaerobic bacteria particularly Pseudomonas spp. In these conditions palmitate accumulated to higher levels than in the strict anaerobic experiment, which seems to be important for the recovery of the methanogenic activity after a transient inhibition. Lower oleate and higher palmitate levels were shown to be advantageous for methane production, possibly because palmitate is less toxic to methanogens than oleate. $^{11,41,42}$ Further studies are needed to better understand the interactions between facultative anaerobic bacteria and other microorganisms within methanogenic communities in continuous bioreactors.

This work encourages further systematic studies on the influence of ORP in the anaerobic digestion process, opening new perspectives on metabolic interactions where complex microbial networks are central. From an applied point of view, ORP is herein proposed as a potentially relevant control variable, whose fine-tune can regulate oleate to palmitate conversion, decreasing the LCFA toxicity toward methanogens, ultimately accelerating the methane production from lipid-rich wastewaters. Ref 24

\section{ASSOCIATED CONTENT}

\section{Supporting Information}

The Supporting Information is available free of charge on the ACS Publications website at DOI: 10.1021/acs.est.8b00894.

Photographs of reactors MaR (a) and AnR (b) in period II; Methane production during the activity assays performed with ethanol as substrate; LCFA concentration during periods I, II, III and IV in the effluent from the CSTR and from the PFR; Confocal Scanning Laser Microscope image of biofilm formed in trial 2 under an HRT of $6 \mathrm{~h}$; Colonies formed by isolates 1 and 2 obtained in Olympus stereomicroscope (SZ40); DGGE profiles of the isolates growing in pure culture (I1 Isolate 1, I2 - Isolate 2) and of the microbial communities present in effluent from the CSTR, in the effluent from the PFR and in the PFR biofilm; LCFA concentrations in the reactors R-I1 and R-I2; Oxidationreduction potential measured in the feeding tanks of reactors MaR and AnR; Oleate concentration at the end of the batch tests performed with the isolates of Pseudomonas spp. at different redox conditions (DOCX)

\section{AUTHOR INFORMATION}

\section{Corresponding Author}

*Phone: +351 253604 417; e-mail: alcina@deb.uminho.pt.

ORCID

M. Alcina Pereira: 0000-0002-7110-1779

\section{Author Contributions}

The manuscript was written through contributions of all authors. All authors have given approval to the final version of the manuscript.

Notes

The authors declare no competing financial interest.

\section{ACKNOWLEDGMENTS}

This study was supported by the Portuguese Foundation for Science and Technology (FCT) under the scope of Project RECI/BBB-EBI/0179/2012 (FCOMP-01-0124-FEDER027462), the strategic funding of UID/BIO/04469/2013 unit and COMPETE 2020 (POCI-01-0145-FEDER-006684), and BioTecNorte operation (NORTE-01-0145-FEDER-000004) funded by European Regional Development Fund under the scope of Norte2020 - Programa Operacional Regional do Norte. Research of M.S.D. and A.J.C. were supported by the European Research Council under the European Union's Seventh Framework Programme (FP/2007-2013)/ERC Grant Agreement No 323009.

\section{ABBREVIATIONS}

$\begin{array}{ll}\text { AD } & \text { anaerobic digestion } \\ \text { AnR } & \text { anaerobic reactor } \\ \text { BLASTN } & \text { standard nucleotide basic local alignment search tool } \\ \text { COD } & \text { chemical oxygen demand } \\ \text { CSTR } & \text { continuous stirred tank reactor } \\ \text { DGGE } & \text { denaturing gradient gel electrophoresis } \\ \text { DNA } & \text { deoxyribonucleic acid } \\ \text { ENA } & \text { European Nucleotide Archive } \\ \text { FID } & \text { flame ionization detector } \\ \text { GC } & \text { gas chromatography } \\ \text { HRT } & \text { hydraulic retention time }\end{array}$


HPLC high-performance liquid chromatography

LCFA long chain fatty acids

MaR microaerophilic reactor

OCT optimum cutting temperature

OLR organic loading rate

ORP oxidation-reduction potential

OTU operational taxonomic units

PBS phosphate-buffered saline

PCR polymerase chain reaction

PFR plug flow reactor

rRNA ribosomal ribonucleic acid

rpm revolutions per minute

STP standard temperature and pressure

VFA volatile fatty acids

VS volatile solids.

\section{REFERENCES}

(1) Sousa, D. Z.; Smidt, H.; Alves, M. M.; Stams, A. J. M. Ecophysiology of syntrophic communities that degrade saturated and unsaturated long-chain fatty acids. FEMS Microbiol. Ecol. 2009, 68 (3), 257-272.

(2) Lalman, J. A.; Bagley, D. M. Anaerobic Degradation and Methanogenic Inhibitory Effects of Oleic and Stearic Acids. Water Res. 2001, 35 (12), 2975-2983.

(3) Canovas-Diaz, M.; Sanchez-Roig, M. J.; Iborra, J. L. Myristic and oleic acid degradation by an acclimated anaerobic consortia: synergistic behavior. In 6th E.C. Conference on Biomass for Energy, Industry, And Environment; Athens, Greece, 1992; pp 580-584.

(4) Weng, C.; Jeris, J. S. Biochemical mechanisms in the methane fermentation of glutamic and oleic acids. Water Res. 1976, 10, 9-18.

(5) Jeganathan, J.; Nakhla, G.; Bassi, A. Long-Term Performance of High-Rate Anaerobic Reactors for the Treatment of Oily Wastewater. Environ. Sci. Technol. 2006, 40 (20), 6466-6472.

(6) Salminen, E.; Einola, J.; Rintala, J. Characterisation and Anaerobic Batch Degradation of Materials Accumulating in Anaerobic Digesters Treating Poultry Slaughterhouse Waste. Environ. Technol. 2001, 22, $577-585$.

(7) Broughton, M. J.; Thiele, J. H.; Birch, E. J.; Cohen, A. Anaerobic batch digestion of sheep tallow. Water Res. 1998, 32 (5), 1423-1428.

(8) Cavaleiro, A. J.; Salvador, A. F.; Alves, J. I.; Alves, M. Continuous high rate anaerobic treatment of oleic acid based wastewater is possible after a step feeding start-up. Environ. Sci. Technol. 2009, 43 (8), 29312936.

(9) Novak, J. T.; Carlson, D. a. Kinetics of Anaerobic Long Chain Fatty Acid Degradation. Water Pollut. Control Fed. 1970, 42 (11), 1932-1943.

(10) Pereira, M. A.; Pires, O. C.; Mota, M.; Alves, M. M. Anaerobic degradation of oleic acid by suspended and granular sludge: identification of palmitic acid as a key intermediate. Water Sci. Technol. 2002, 45 (10), 139-144.

(11) Pereira, M. A.; Pires, O. C.; Mota, M.; Alves, M. M. Anaerobic biodegradation of oleic and palmitic acids: evidence of mass transfer limitations caused by long chain fatty acid accumulation onto the anaerobic sludge. Biotechnol. Bioeng. 2005, 92 (1), 15-23.

(12) Cavaleiro, A. J.; Pereira, M. A.; Guedes, A. P.; Stams, A. J. M.; Alves, M. M.; Sousa, D. Z. Conversion of Cn-Unsaturated into Cn-2Saturated LCFA Can Occur Uncoupled from Methanogenesis in Anaerobic Bioreactors. Environ. Sci. Technol. 2016, 50 (6), 3082-3090.

(13) Pereira, M. A.; Roest, K.; Stams, A. J. M.; Mota, M.; Alves, M.; Akkermans, A. D. L. Molecular monitoring of microbial diversity in expanded granular sludge bed (EGSB) reactors treating oleic acid. FEMS Microbiol. Ecol. 2002, 41 (2), 95-103.

(14) Baserba, M. G.; Angelidaki, I.; Karakashev, D. Effect of continuous oleate addition on microbial communities involved in anaerobic digestion process. Bioresour. Technol. 2012, 106, 74-81.

(15) Botheju, D.; Bakke, R. Oxygen Effects in Anaerobic Digestion A Review. Open Waste Manage. J. 2011, 3901, 1-19.
(16) Joubert, W. A.; Britz, T. J. Characterization of Aerobic, Facultative Anaerobic, and Anaerobic Bacteria in an Acidogenic Phase Reactor and Their Metabolite Formation. Microb. Ecol. 1987, 13 (2), $159-168$.

(17) Gerritse, J.; Gottschal, J. C. Two-membered mixed cultures of methanogenic and aerobic bacteria in O2-limited chemostats. J. Gen. Microbiol. 1993, 139, 1853-1860.

(18) Kato, M. T.; Field, J. A.; Lettinga, G. Anaerobe Tolerance to Oxygen and the Potentials of Anaerobic and Aerobic Cocultures for wastewater treatment. Braz. J. Chem. Eng. 1997, 14 (4), 1-12.

(19) Pedizzi, C.; Regueiro, L.; Rodriguez-Verde, I.; Lema, J. M.; Carballa, M. Effect of oxygen on the microbial activities of thermophilic anaerobic biomass. Bioresour. Technol. 2016, 211, 765768 .

(20) Tsapekos, P.; Kougias, P. G.; Vasileiou, S. A.; Lyberatos, G.; Angelidaki, I. Effect of micro-aeration and inoculum type on the biodegradation of lignocellulosic substrate. Bioresour. Technol. 2017, 225, 246-253.

(21) Montalvo, S.; Huiliñir, C.; Ojeda, F.; Castillo, A.; Lillo, L.; Guerrero, L. Microaerobic pretreatment of sewage sludge: Effect of air $\mathrm{fl}$ ow rate, pretreatment time and temperature on the aerobic process and methane generation. Int. Biodeterior. Biodegrad. 2016, 110, 1-7.

(22) Zouari, N.; H. A. J. Improvement by Micro-Aeration of Anaerobic Digestion of Slaughterhouse Wastewater At $38^{\circ} \mathrm{C}$. Int. J. Innov. Res. Sci. Eng. Technol. 2015, 4 (3), 807-816.

(23) Nurliyana, M. Y.; H'ng, P. S.; Rasmina, H.; Kalsom, M. S. U.; Chin, K. L.; Lee, S. H.; Lum, W. C.; Khoo, G. D. Effect of C/N ratio in methane productivity and biodegradability during facultative codigestion of palm oil mill effluent and empty fruit bunch. Ind. Crops Prod. 2015, 76, 409-415.

(24) Alves, M. M.; Mota Vieira, J. A.; Álvares Pereira, R. M.; Pereira, M. A.; Mota, M. Effects of lipids and oleic acid on biomass development in anaerobic fixed-bed reactors. Part II: Oleic acid toxicity and biodegradability. Water Res. 2001, 35 (1), 264-270.

(25) Alves, M. M.; Vieira, J. A.; Pereira, R. M.; Pereira, M. A.; Mota, M. Effect of lipids and oleic acid on biomass development in anaerobic fixed-bed reactors. Part I: Biofilm growth and activity. Water Res. 2001, 35 (1), 255-263.

(26) Colleran, E.; Concannon, F.; Golden, T.; Geoghegan, F.; Crumlish, B.; Killilea, E.; Henry, M.; Coates, J. Use of methanogenic activity tests to characterize anaerobic sludges, screen for anaerobic biodegradability and determine toxicity thresholds against individual anaerobic trophic. Water Sci. Technol. 1992, 25 (7), 31-40.

(27) Stams, A. J. M.; Van Dijk, J. B.; Dijkema, C.; Plugge, M.; Dijk, J. B. V. A. N.; Dijkema, C. O. R.; Plugge, C. M. Growth of Syntrophic Propionate-Oxidizing Bacteria with Fumarate in the Absence of Methanogenic Bacteria Growth of Syntrophic Propionate-Oxidizing Bacteria with Fumarate in the Absence of Methanogenic Bacteria. Appl. Environ. Microbiol. 1993, 59, 1114-1119.

(28) APHA; AWWA; WPCF. Standard Methods for the Examination of Water and Wastewater; American Public Health Association.; Washington D.C, 1999.

(29) Neves, L.; Pereira, M. a.; Mota, M.; Alves, M. M. Detection and quantification of long chain fatty acids in liquid and solid samples and its relevance to understand anaerobic digestion of lipids. Bioresour. Technol. 2009, 100 (1), 91-96.

(30) Caporaso, J. G.; Lauber, C. L.; Walters, W. A.; Berg-lyons, D.; Lozupone, C. A.; Turnbaugh, P. J.; Fierer, N.; Knight, R. Global patterns of $16 \mathrm{~S}$ rRNA diversity at a depth of millions of sequences per sample. Proc. Natl. Acad. Sci. U. S. A. 2011, 108, 4516-4522.

(31) Paulo, A. M. S.; Salvador, A. F.; Alves, J. I.; Castro, R.; Langenhoff, A. A. M.; Stams, A. J. M.; Cavaleiro, A. J. Enhancement of methane production from 1-hexadecene by additional electron donors. Microb. Biotechnol. 2017, DOI: 10.1111/1751-7915.12886 (Published ahead of print).

(32) Sousa, D. Z.; Pereira, M. A.; Smidt, H.; Stams, A. J. M.; Alves, M. M. Molecular assessment of complex microbial communities degrading long chain fatty acids in methanogenic bioreactors. FEMS Microbiol. Ecol. 2007, 60 (2), 252-265. 
(33) Lane, D. J. 16S/23S rRNA sequencing. In Stackebrandt, E., Goodfellow, M., Eds.; Nucleic Acid Tech. Bact. Syst. 1991, 115-175.

(34) Nübel, U.; Engelen, B.; Felske, a.; Snaidr, J.; Wieshuber, a.; Amann, R. I.; Ludwig, W.; Backhaus, H.; Engelen, B.; Felske, A. Sequence heterogeneities of genes encoding $16 \mathrm{~S}$ rRNAs in Paenibacillus polymyxa detected by temperature gradient gel electrophoresis. Sequence Heterogeneities of Genes Encoding 16S rRNAs in Paenibacillus polymyxa Detected by Temperature Gradient Gel Elect. J. Bacteriol. 1996, 178 (19), 5636-5643.

(35) Zoetendal, E. G.; Akkermans, A. D. L.; Vliet, W. M. A.; Visser, A. G. M. De; Vos, W. M. De. The Host Genotype Affects the Bacterial Community in the Human Gastrointestinal Tract. Microb. Ecol. Health Dis. 2001, 13, 129-134.

(36) Sanguinetti, C.; Dias, N. E.; Simpson, A. Rapid Silver Staining and Recovery of PCR Products Separated on Polyacrylamide Gels. Biotechniques 1994, 17 (5), 914-921.

(37) Gomila, M.; Peña, A.; Mulet, M.; Lalucat, J. Phylogenomics and systematics in. Front. Microbiol. 2015, 6, 1-13.

(38) Stams, A. J. M.; Sousa, D. Z.; Kleerebezem, R.; Plugge, C. M. Role of syntrophic microbial communities in high-rate methanogenic bioreactors. Water Sci. Technol. 2012, 66 (2), 352-362.

(39) Pereira, M. A.; Mota, M.; Alves, M. M. Operation of an anaerobic filter and an EGSB reactor for the treatment of an oleic acidbased effluent: influence of inoculum quality. Process Biochem. 2002, 37 (9), 1025-1031.

(40) Kim, S.-H.; Han, S.-K.; Shin, H.-S. Kinetics of LCFA Inhibition on Acetoclastic Methanogenesis, Propionate Degradation and $\beta$ Oxidation. J. Environ. Sci. Health, Part A: Toxic/Hazard. Subst. Environ. Eng. 2004, 39 (4), 1025-1037.

(41) Sousa, D. Z.; Salvador, A. F.; Ramos, J.; Guedes, A. P.; Barbosa, S.; Stams, A. J. M.; Alves, M. M.; Pereira, M. A. Activity and viability of methanogens in anaerobic digestion of unsaturated and saturated longchain fatty acids. Appl. Environ. Microbiol. 2013, 79 (14), 4239-4245.

(42) Silva, S. A.; Salvador, A. F.; Cavaleiro, A. J.; Pereira, M. A.; Stams, A. J. M.; Alves, M. M.; Sousa, D. Z. Toxicity of long chain fatty acids towards acetate conversion by Methanosaeta concilii and Methanosarcina mazei. Microb. Biotechnol. 2016, 9, 514-518.

(43) Angelidaki, I.; Ahring, B. K. Effects of free long-chain fatty acids on thermophilic anaerobic digestion. Appl. Microbiol. Biotechnol. 1992, 37, 808-812.

(44) Rinzema, A.; Boone, M.; Knippenberg, K. Van; Lettinga, G. Bactericidal effect of long chain fatty acids in anaerobic digestion. Water Environ. Res. 1994, 66 (1), 40-49.

(45) Pereira, M. A.; Sousa, D. Z.; Mota, M.; Alves, M. M. Mineralization of LCFA associated with anaerobic sludge: Kinetics, enhancement of methanogenic activity, and effect of VFA. Biotechnol. Bioeng. 2004, 88 (4), 502-511.

(46) Costerton, J. W.; Cheng, K. J.; Geesey, G. G.; Ladd, T. I.; Nickel, J. C.; Dasgupta, M.; Marrie, T. J. Bacterial Biofilms in Nature and Disease. Annu. Rev. Microbiol. 1987, 41 (1), 435-464.

(47) Heffernan, B.; Murphy, C. D.; Casey, E. Comparison of planktonic and biofilm cultures of Pseudomonas fluorescens dsm 8341 cells grown on Fluoroacetate. Appl. Environ. Microbiol. 2009, 75 (9), 2899-2907. 